\title{
Effect of feed slurry dilution and total solids on specific biogas production by anaerobic digestion in batch and semi-batch reactors
}

\author{
Gautham P. Jeppu $^{1}$ D . Jayalal Janardhan ${ }^{1} \cdot$ Shivakumara Kaup $^{1} \cdot$ Anish Janardhanan ${ }^{1} \cdot$ Shakeib Mohammed $^{1}$. \\ Sharath Acharya ${ }^{1}$
}

Received: 29 August 2020 / Accepted: 6 September 2021 / Published online: 21 September 2021

(c) The Author(s) 2021

\begin{abstract}
Biomass from various sources such as cow dung is a significant source of renewable energy (as biogas) in many regions globally, especially in India, Africa, Brazil, and China. However, biogas production from biomass such as cattle dung is a slow, inefficient biochemical process, and the specific biogas produced per $\mathrm{kg}$ of biomass is relatively small. The improvement of specific biogas production efficiency using various dilution ratios (and, hence, total solids [TS]) is investigated in this work. A wide range of feed dilution (FD) ratios of cow dung: water (CD: W) was tested in batch biogas digesters with total solids ranging from $1 \%$ to $12.5 \%$ and FD ratio ranging from $2: 1$ to $1: 20$. To further verify the results from the above batch experiments, semi-batch experiments representative of field-scale biodigesters were conducted. Semi-batch reactors have a steady-state process, unlike batch reactors, which have an unsteady state process. Our results suggested that specific biogas production (mL/g VS) increased continuously when the total solids decreased from $12.5 \%$ to $1 \%$ (or when dilution increased). Our experiments also indicate that the commonly used 1:1 feed dilution ratio (TS $10 \%$ for cow dung) does not produce the maximum specific biogas production. The possible reason for this could be that anaerobic digestion at higher total solids is rate limited due to substrate inhibition, mass transfer limitations, and viscous mixing problems that arise at higher total solids concentration. Hence, a higher feed dilution ratio between 1:2 and 1:4 (TS between 4 and 6.7\%) is recommended for a more efficient biomass utilization of cowdung. Empirical relationships were also developed for variation of specific biogas yield with the total solids content of the cow dung slurry.
\end{abstract}

Gautham P. Jeppu

gautham.jeppu@gmail.com

1 Department of Chemical Engineering, Manipal Institute of Technology, Manipal Academy of Higher Education (MAHE), Manipal, Udupi, Karnataka 576104, India 


\section{Graphic abstract}

\section{Batch anaerobic digester experiments}
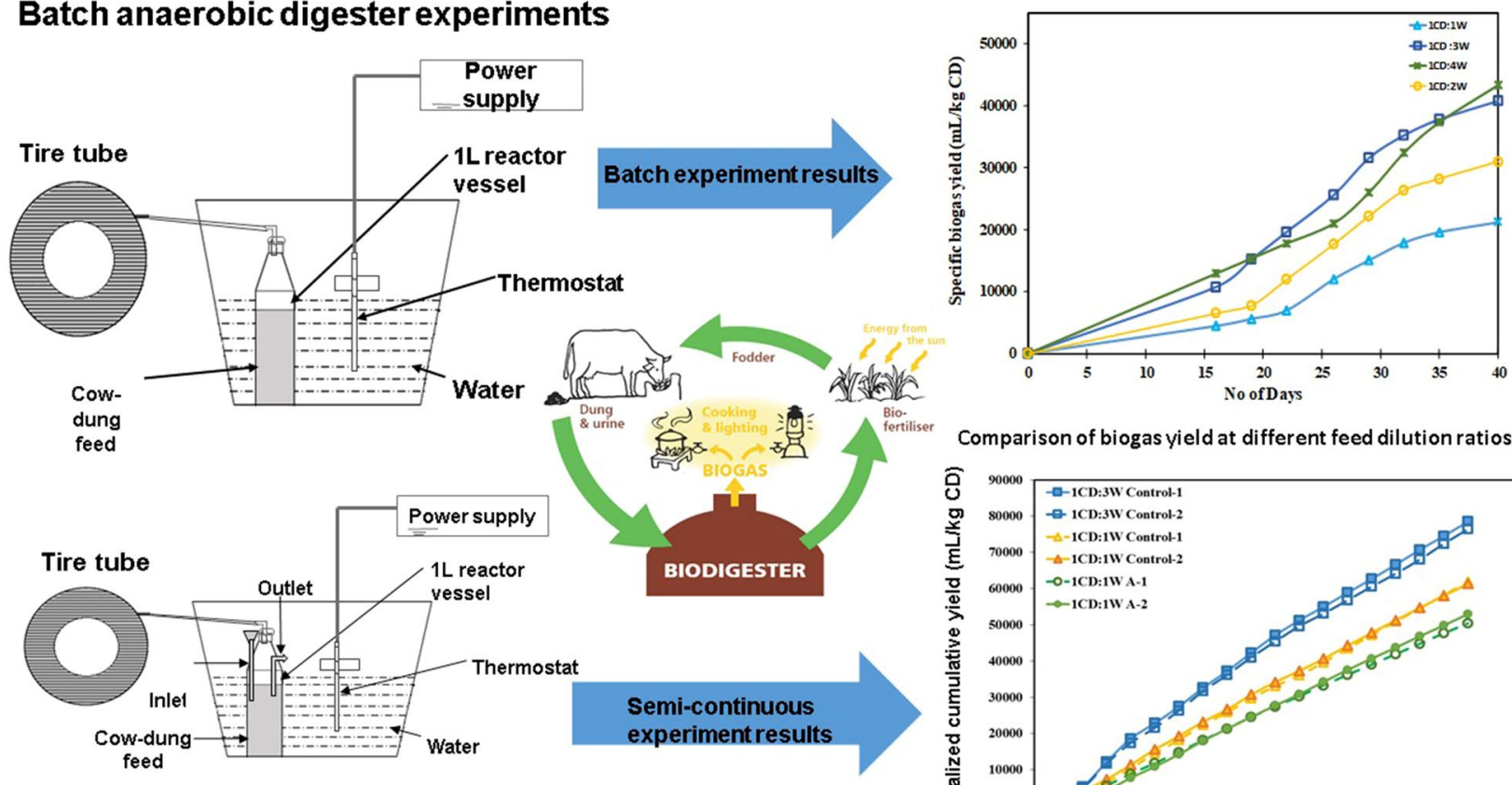

Comparison of biogas yield at different feed dilution ratios.

\section{Semi-continuous anaerobic digester experiments}

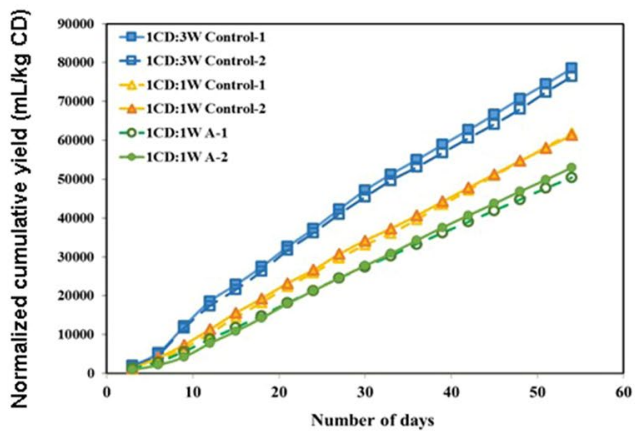

Keywords Biogas $\cdot$ Total solids $\cdot$ Feed dilution ratio $\cdot$ Cow dung $\cdot$ Anaerobic digestion $\cdot$ Biodigesters $\cdot$ Mixing ratio $\cdot$ Semibatch

\section{Novelty statement}

1. The effect of total solids on biogas yield from cow dung has been studied at a wide range of a wide range of dilutions (2:1-1:19) and corresponding total solids $(1 \%-13.5 \%)$, and at very low total solids (TS $<4 \%)$.

2. A mathematical form of the relationship between TS\% and specific biogas yield (mL/g VS) has been developed for cow dung.

3. Most of the previous studies have used batch experiments only. In this study additionally semi-batch experiments (which represent actual field-scale digestors) were conducted to study the feed dilution ratio on biogas yield.

4. The effect of feed dilution ratio (and, hence, total solids) on substrate inhibition and biogas yield has been investigated systematically under both controlled temperature conditions and ambient temperature conditions.

5. A new method that was more accurate to measure the total solids content for manure and viscous biomass has been used.
6. It has been shown that the use of higher dilution of feed dilution of cow dung in semi-batch experiments increased the biogas yield by more than $30 \%$. The combined use of controlled mesophilic temperature and a higher dilution ratio can increase biogas production by nearly $40 \%-45 \%$. This combined increase has not been reported.

7. A review and comparison of experimental data are made from literature for the effect of total solids on specific biogas production for cow dung, and the best total solids and feed dilution ratio range is reported.

\section{Introduction}

Solid waste disposal is increasingly becoming a challenge due to population rise, and the importance of renewable green energy is now more than ever. The cattle population in the world has grown steadily and is estimated to be around 1.6 billion [1]. Improper disposal of cattle dung is an environmental and health challenge that can be overcome by using cattle dung in biogas plants, which simultaneously produces valuable cooking gas and organic fertilizer. There 
are over 4.5 million biogas plants in India and over 27 million biogas plants in China alone [2]. Thus, the potential for biogas production from cattle manure and agricultural waste is very high. Even a slight increase of $25 \%$ in biogas production efficiency can cut down the use of fossil fuels by a significant amount.

However, biogas production is a slow biochemical process, and the biogas yield per $\mathrm{kg}$ of biomass is low. The present study attempts to increase the efficiency of biogas production (by $>30 \%$ ) and, thus, the overall productivity by optimizing the feed dilution ratio and the total solids.

\section{Improvement of biogas production}

Previous research has suggested that biogas yield can be increased by using several methods such as a mesophilic continuously stirred tank reactor, hydrothermal fiber liquefaction process, and the bacteria species such as Fibrobacter Succinogenes [3]. An increase in biogas production from $15 \%$ to $20 \%$ can be obtained through such methods. The effects of feed to inoculum ratio and co-digestion on biogas production increase have also been studied [4].

Pretreatment of agricultural wastes using alkali, ultrasound, acid, or mechanical maceration has been shown to increase the biogas yield [5-8]. Several studies have reported using mineral additives for increasing biogas production, such as iron-oxides, ferric chloride, ferrous sulfate, and nickel chloride [9-13]. Some of these techniques may be costly, involve more energy, or are too high-tech for use in farms by peasants.

\section{Total solids/dilution ratio}

Total solids (TS) and temperature were shown to be important factors affecting biogas production [14-16]. The total solids of anaerobic digestors are determined by the dilution level of the feed mass, which can be represented by the dilution ratio $(F D R)$. FDR is defined as the ratio of the mass of feed substrate to the mass of water used for dilution.

Feed dilution ratio or dilution ratio is defined as the ratio of the mass of feed substrate to the mass of water used for dilution. Since the specific gravity of cow dung and water nearly equal to 1 , so FD ratio can be approximated as the ratio of respective volumes.

Feed Dilution Ratio $($ FDR $)=\frac{\text { Mass of feed biomass }}{\text { Mass of water }}$.

In a field-scale biogas plant, practically, the dilution ratio (FDR) decides the TS of the digester. Hence, biogas production's efficiency and is, therefore, the most critical operating parameter of a biogas plant. The dilution ratio, which gives the maximum specific biogas yield (MSBY) per gram of substrate, is particularly of interest for the most efficient biomass valorization.

\section{Effect of dilution ratio/TS on biogas production from food waste}

For food wastes, recent studies have shown that the biogas yield was found to be higher at lower total solids (higher dilutions) of $4.5 \%$ total solids [17] and 7.5\% total solids [18]. Leite et al. [19] studied co-digestion of food waste and sewage sludge and showed that the highest biogas yield was at a lower total solid of $3 \%$ and the smallest size of particles. Battista et al. [20]studied the digestion of olive oil production wastes. They suggested that dilution increased the specific biogas production (per kg substrate) due to the elimination of inhibition effect by polyphenols and suggested the most efficient TS was $8 \%$. For agricultural wastes, Chandra et al. [21] found that a dilution ratio of 1:4 was best for Jatropha Curcas seed powder and 1:3.5 for Pongamia Pinnata seed powder.

\section{Effect of dilution ratio/TS on biogas production from cow dung}

Traditionally in India, biogas plants are run at a dilution ratio of cow dung: water of 1:1 [22], which corresponds to a total solid of approximately $10 \%$ [15]. The total solids of fresh cow dung have been reported to be around $17 \%-21 \%$ $[15,23,24]$. The previous studies on the effect of dilution ratio or total solids on biogas yield have not given uniform results. Several studies have reported different values for the best TS (and dilution ratio) for maximum specific biogas yield (L/kg-substrate, L/kg-TS, L/kg-VS). Itodo and Awulu [23] suggested that the specific biogas yield increased with decreasing TS for cattle, piggery, and poultry wastes and recommended biogas production at lower TS values (high FDR) for maximum specific biogas yield. The reduction in specific biogas yield with higher TS was attributed to inhibition, mixing limitations, and mass transfer issues [25-27]. In another study, a dilution ratio of 1:2 (cow dung: water), (TS $\sim 6.6 \%$ ) was found to have higher biogas yield [28]; however, higher dilution ratios were not studied. Zennaki et al. [29] suggested that a TS of 7\%-9\% gave better biogas yield in biogas reactors. In contrast, Singh et al. [15] suggested that a total solid of $9-13.5 \%($ FDR $=0.5-1.22)$ was suggested for biogas production. However, both these studies were based on total biogas yield (L biogas/L reactor volume) and not based on specific biogas yield (L/kg-TS. Similarly, the effect of total solids on biogas yield for cattle manure using three different TS values was studied by [30], who suggested that $8 \% \mathrm{TS}(\mathrm{FDR}=1.5)$ was the most efficient TS for producing biogas. 
Many of the above studies have focused on maximum total biogas $(\mathrm{mL})$ yield and not maximum specific biogas yield (mL/g VS). Also, most of the above studies were done in batch reactors (except [15]), and studies from batch reactors and cannot be directly applied to continuous running biodigesters, which operate in semi-batch mode [31]. For example, the extent of biomass degradation and biogas generation was different in batch and semi-batch by nearly $20 \%$ [31]. Some of the earlier studies were done in batch experiments without a controlled temperature (e.g., [23]). Hence, it is required to study in detail the effect of feed dilution ratio under controlled temperature and ambient temperature conditions in both batch and semi-batch reactors. Some of the earlier studies were done in batch experiments without a controlled temperature (e.g., [23]). Hence, it is required to study in detail the effect of feed dilution ratio under controlled temperature and varying temperature conditions in both batch and semi-batch reactors.

Most biogas plants (operated by farmers and peasants) in India and China commonly use a dilution ratio of 1:1 mixture of cow dung and water, based on studies from the 1980s $[15,22]$. In this twenty-first century era of the quest for high energy efficiency, the dilution ratio needs to be reinvestigated to find the dilution ratio (and, hence, TS) for the highest specific biogas production ( $\mathrm{L} / \mathrm{kg}$-biomass). There is some incongruence in the literature about the best feed dilution ratio and total solids to be used, causing confusion in the best operation and design practices of biodigesters for maximum specific biogas yield and energy efficiency. Authors could not find any recent research with conclusive values of feed dilution ratio or TS, which gives the maximum specific production of biogas from cow dung using daily-fed semi-batch reactors over a long retention time and for nearly 40 days required for the stabilization of the reactor.

The objective of this paper was to clearly study the effect of feed dilution ratio (and a wide range of total solids) on maximum specific biogas yield for cow dung in batch and semi-batch reactors and to determine the feed dilution ratio for the maximum specific biogas yield. The authors have presented herein the experimental data of work done over three years and nearly 1000 man-days of experimental work. The authors have also reviewed and summarized the relevant findings from the literature.

\section{Experimental methods}

\section{Experiments in batch reactors}

To study the effect of different feed dilution ratios for biogas optimization, experiments were conducted in batch reactors and semi-batch reactors. The batch experimental setup used is given below in Fig. 1. A number of such reactors were made and operated in parallel. The batch biodigesters shown in the figure below consisted of a $1.25 \mathrm{~L}$ reactor vessel, which was covered with aluminum foil. $1 \mathrm{~L}$ volume of the reactor was used for reactor feed, and the rest $0.25 \mathrm{~L}$ was empty.

A thermostat was used to control the temperature at $37{ }^{\circ} \mathrm{C}$ for control temperature experiments by placing the reactor in a water bath. Most of the experiments except the ones mentioned as controlled temperature) were conducted under room temperature conditions where no water bath and thermostat were used. The biogas generated was released into an inverted vessel bottle with water. The water displacement method was used to measure the volume of biogas produced. The water displaced is collected in a measuring jar. The whole system was made airtight so as to make it anaerobic after feeding was done. During the start-up period, the biogas reactors were inoculated with $50 \mathrm{~g}$ digestate from an existing biogas plant along with $950 \mathrm{~g}$ of cow dung slurry. Thereafter, the reactor was left for 2-4 days before starting
Fig. 1 Schematic representation of the batch experimental setup. Several such reactors were used

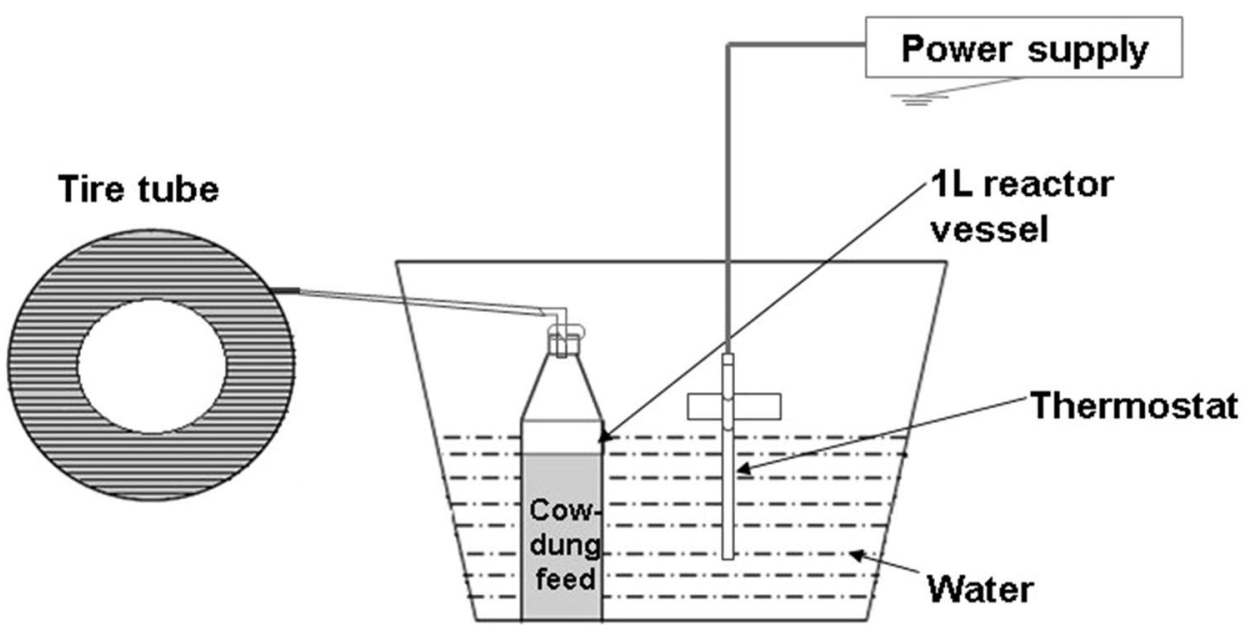


to measure the biogas. After that, the daily reading of biogas produced was taken for nearly 40 days or till the biogas production stops. The biogas collected was tested for the percentage of carbon dioxide and methane produced (this procedure was carried out using the needle from a syringe). Ambient temperature reactors were denoted by the letter A or AT, and the ones with temperature control were denoted with the letter $\mathrm{C}$.

Specific cow dung: water ratio (CD: $\mathrm{W}$ ) was maintained in all the reactors. For example, in the 1:1 FD ratio reactor, $1000 \mathrm{~g}$ of cow dung was taken with $1000 \mathrm{~mL}$ of dilution water, which had $100 \mathrm{~mL}$ of inoculum in it.

\section{Experiments in semi-batch reactors}

The semi-batch system shown in Fig. 2 below was representative of a field-scale biogas plant. Each of these experiments took nearly two months to complete. The semi-batch reactor shown below consisted of a $2.25 \mathrm{~L}$ reactor vessel covered with aluminum foil and placed in a temperature-controlled water bath. The reactor had an inlet to feed the biomass and an outlet for the digestate (this provision was not present in the batch reactor). A number of such semi-batch reactors were operated in parallel. A thermostat was used to control the temperature at $37^{\circ} \mathrm{C}$ for some experiments (control experiments denoted by $\mathrm{C}$ ). Some of the experiments were conducted under ambient (room) temperature conditions (denoted by the letter A or AT), where no water bath and thermostat were used. The whole system was made airtight so as to make it anaerobic. The inlet and outlet pipes were narrow and had a water seal. The inlet was capped after feeding the reactor. The biogas generated was collected in an expandable tire tube. The water displacement method was later used to measure the volume of biogas produced. The water displaced was collected and measured in a measuring jar.
The required feed dilution ratio of cow dung: water ratio $(\mathrm{CD}: \mathrm{W})$ was maintained in all the reactors. For example, in the 1:1 FD ratio experiment, $1000 \mathrm{~g}$ of cow dung was taken with $900 \mathrm{~mL}$ of dilution water and $100 \mathrm{~mL}$ of inoculum, amounting to a total of $2 \mathrm{~L}$ of the slurry. The daily feed to the semi-batch reactors was calculated based on the hydraulic retention time of the cow dung (40 days).

The reactor was initially left for four days before starting to measure the biogas, after which the daily feeding of 50 $\mathrm{g}$ of cow dung slurry was started. The daily feed of $50 \mathrm{~g}$ of slurry included cow dung and water in the respective feed dilution ratio of each reactor. For example, for the 1:1 FD ratio reactor, $25 \mathrm{~g}$ of raw cow dung was fed with $25 \mathrm{~g}$ of distilled water.

The biogas volume readings were taken once in three days. The semi-batch reactors reached a steady state after 20-25 days. The experiment was continued until 50 days until the biogas production reached a steady state. The biogas collected was tested for the percentage of carbon dioxide and methane produced using a GC.

\section{Analysis of parameters}

\section{Total solids (TS)}

The determination of total solids is commonly done using the standard method by American Public Health Authority or solids (APHA [31]). The standard procedure for measurement of total solids (APHA [31]) for water and wastewater was as follows: A known weight of cow dung was taken in a petri dish. The sample was dried at a temperature of $105^{\circ} \mathrm{C}$ for $6 \mathrm{~h}$. The final weight was noted, and the total solids (TS) $\%$ was taken as the percentage of the weight of the final sample/weight of the initial sample. However, the authors noticed that for cow dung during oven drying process, there was the formation of lumps and top crusts, leading to

Fig. 2 Schematic diagram of the semi-batch reactor setup. Several such reactors were used

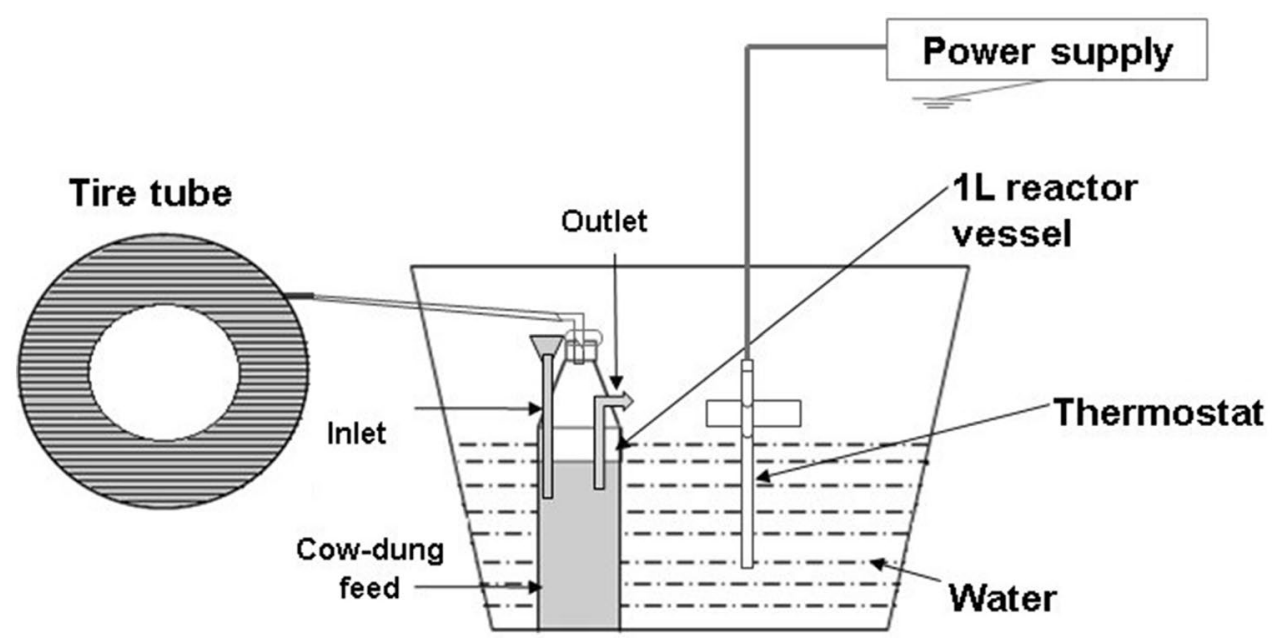


non-uniform drying and trapped moisture, which can cause errors in TS measurement.

Hence, a new procedure (dilution method) was developed for measuring the total solids of cattle manure. A known weight of cow dung $(2 \mathrm{~g})$ was diluted with a known volume of water $(5 \mathrm{~mL})$ in a petri dish. The resultant slurry was mixed well to crush any lumps and to form a uniform and dilute slurry. The mixture was dried in a preheated oven at $105^{\circ} \mathrm{C}$ for $5 \mathrm{~h}$. This procedure avoided non-uniform drying due to lump and crust formation and gave consistent results in less time.

\section{Volatile solids and fixed solids}

The fixed solids were measured by incineration of a known weight of a sample using a muffle furnace at $500{ }^{\circ} \mathrm{C}$ for $2 \mathrm{~h}$ and measuring the residue. The volatile solids were calculated by subtracting the fixed solids from the total solids.

\section{Biogas analysis}

Biogas composition was determined with a gas chromatograph (Chemito GC-8610 model) with a thermal conductivity detector (TCD), using a packed column (Spherocarb column $3 \mathrm{~m} \mathrm{1/8}$ in, SS). The carrier gas was nitrogen (column flow: $27 \mathrm{~mL} / \mathrm{min}$ ). The oven was kept at an isothermal temperature of $50^{\circ} \mathrm{C}$, and injector and detector temperatures were kept at $200{ }^{\circ} \mathrm{C}$, respectively. A calibration curve for different methane gas compositions using standard $\mathrm{CH}_{4}$ gas (obtained from Bhuruka gases Ltd) was plotted.

\section{Results}

\section{Experiment set 1: effects of feed dilution ratio (FD ratio) on biogas yield in batch reactors}

Various feed dilution ratios (ranging from 1:1 to 1:4) of the mass of cow dung to a mass of water were studied to compare the biogas production in batch reactors shown in Fig. 1. The total solids of the cow dung used were measured to be $16.22 \%$, and the volatile solid content was $12.69 \%$ of the weight. For example, in the 1:1 FD ratio experiment, $500 \mathrm{~g}$ of cow dung was taken with $450 \mathrm{~g}$ of distilled water and $50 \mathrm{~g}$ of inoculum, which was 1:1 dilution in mass since the density of water and the inoculum was taken as approximately as $1 \mathrm{~g} / \mathrm{mL}$. The digestion process was carried out in $1 \mathrm{~L}$ batch experimental setups shown in Fig. 1. Several such reactors were operated in parallel. The dilution of the raw feed helps in better mixing in the digester. The amount of biogas produced was normalized to $1 \mathrm{~kg}$ of cow dung so as to compare it with the rest of the experiments. The results are shown in Fig. 3 below.

In the above graph (Fig. 3), it was observed that the 1:1 FD ratio produced the least amount of biogas. As the dilution increased, the biogas production per $\mathrm{kg}$ of cow dung increased. The 1:2.5 FD ratio reactor produced around $17 \%$ more biogas when compared to the $1: 1 \mathrm{FD}$ ratio The 1:3 dilution ratio reactor produced around $30 \%$ more biogas when compared to the 1:1 dilution ratio. When the FD ratio increased to $1: 3.5$ and 1:4, there was no further significant increase in biogas production. The biogas yield per gram of VS was $227 \mathrm{~mL}, 265 \mathrm{~mL}, 273 \mathrm{~mL}, 270 \mathrm{~mL}$, and $277 \mathrm{~mL}$ for $1: 1,1: 2.5,1: 3,1: 3.5$, and 1:4 FD ratios, respectively. From these results, we can infer that the $1: 1$ FD ratio reactor could be inhibited, and the inhibition was removed by the dilution and higher FD ratio up to $1: 3$ $(\mathrm{CD}: \mathrm{W})$; beyond 1:3 FD ratio, there was no further appreciable increase of biogas production.

\section{Experiment set 2: effects of feed dilution ratio (FD ratio) on biogas yield in batch reactors under ambient temperature conditions}

The previous experiment sets 1 was done under controlled temperature conditions using a thermostat and water bath. However, the actual biogas reactors in the field are under varying temperature conditions. The ambient temperature increases during the day and decreases at night in a cyclic fashion. To study the effect of feed dilution ratio under such varying temperature conditions, experiments were conducted furthermore under ambient conditions without the use of the water bath and thermostat. Various feed dilution ratios (ranging from 1:1 to 1:4) of the mass of cow dung to a mass of water were studied to compare the biogas production in four batch reactors in one-liter batch experimental setups,

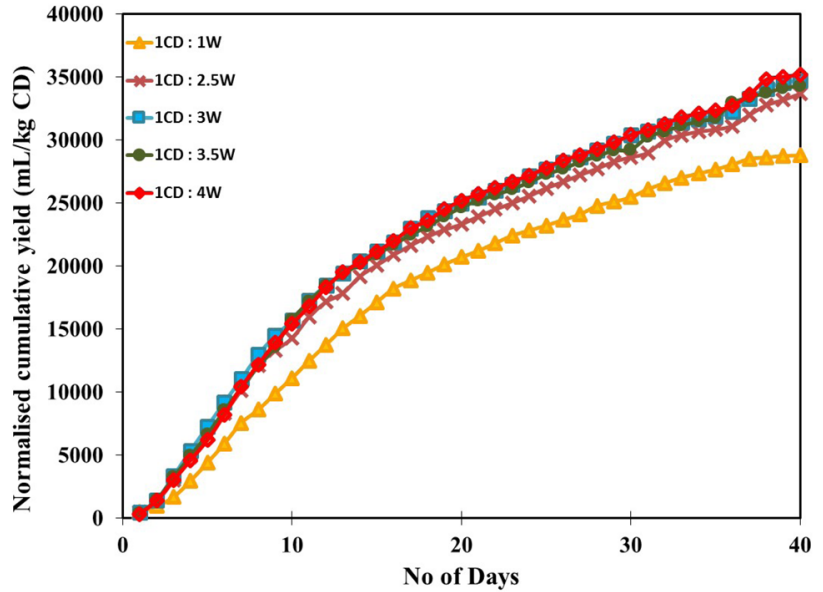

Fig. 3 The cumulative graph to compare biogas yield at different feed dilution ratio. $C D$ cow dung, $W$ water 
as shown in Fig. 1. The total solids of the cow dung used were measured to be $19.22 \%$, and the volatile solid content was $79.1 \%$ of the TS. The amount of biogas produced was normalized to $1 \mathrm{~kg}$ of cow dung so as to compare it with the rest of the experiments and is shown in the graph below (Fig. 4). Methane percentage is reported in Table 1.

The experimental results are shown in the graph above (Fig. 4). It is observed that the 1:1 FD ratio produced the least amount of biogas. As the dilution increased, the biogas production per $\mathrm{kg}$ of cow dung increased. When the FD ratio increased to $1: 3.5$ and 1:4, there was a slight increase in biogas production.

When the FD ratio increased to $1: 4$, there was no further increase of biogas production and produced almost the same amount of biogas yield as the 1:3 FD ratio reactor, and the results followed an almost similar trend as experiment 1 . The biogas yield per gram of VS was $153 \mathrm{~mL}, 203.6 \mathrm{~mL}, 237 \mathrm{~mL}$, and $285 \mathrm{~mL}$ for 1:1, 1:2,1:3, and 1:4 FD ratios, respectively. These results show that under ambient varying temperature conditions, the biogas produced increased with dilution until the dilution up to $1: 4$. The results our semi-batch reactor experiments [32] support the above findings in batch reactors suggesting our results apply to field-scale biogas digesters.

\section{Experiment set 3}

The previous experiment sets 1 and 2 were done under a limited dilution ratio range. To further study the effect of

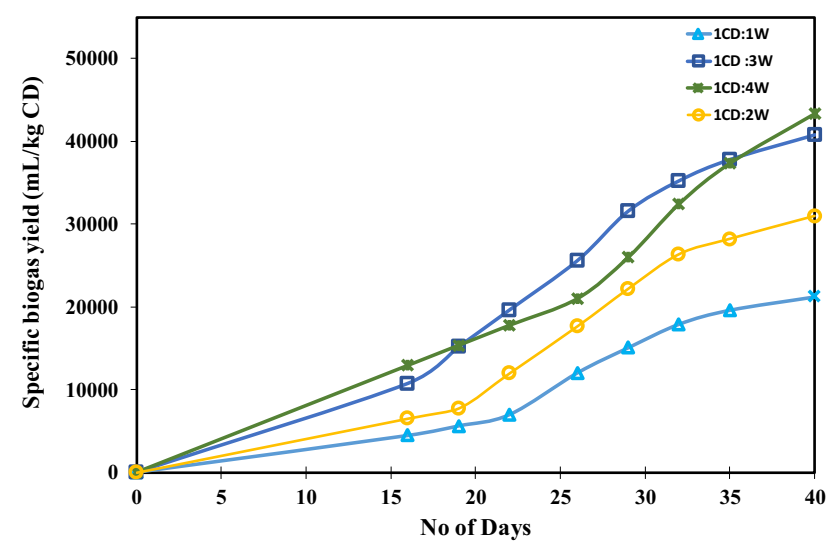

Fig. 4 The cumulative graph to compare biogas yield at different feed dilution ratio. $C D$ cow dung, $W$ water

Table 1 Methane \% of different reactors

\begin{tabular}{lll}
\hline SI. no. & Ratio & Methane\% \\
\hline 1 & 1CD: 1W & 43.6 \\
2 & 1CD:2W & 44.2 \\
3 & 1CD:3W & 41.5 \\
4 & 1CD:4W & 42.6 \\
\hline
\end{tabular}

total solids, a wide range of dilution ratios from 2:1 to 1:20 were investigated in experiment Set 3. Various feed dilution ratios (ranging from 2:1 to 1:20) of the mass of cow dung to a mass of water were studied to compare the biogas production in four batch reactors in one-liter batch experimental setups as shown in Fig. 1. The experiments were done under room temperature (ambient) conditions. The experiment was conducted in batch reactors for 56 days for detailed observation of biogas production. The gas produced was measured every three days to observe the daily production. The biogas produced was collected into empty tire tubes, and readings were taken by releasing the gas to an inverted measuring cylinder filled with water in a tub of water. The total solids of the cow dung used were measured to be $20.32 \%$, and the volatile solid content was $78.83 \%$ of the TS. The amount of biogas produced was normalized to $1 \mathrm{~kg}$ of cow dung so as to compare it with the rest of the experiments and is shown in the graph below (Fig. 5).

The lowest specific biogas production was at an FD ratio of $2: 1$. The specific biogas production increased in the order $2: 1<1: 1<1: 2.5<1: 3<1: 4<1: 5<1: 7<1: 9<10: 19$. The biogas produced was flammable even at an FD ratio of 1:19, which had only $1 \%$ TS. This indicates that the FD ratio has a significant effect on specific biogas production. At higher FD ratios $>1: 9$, higher specific biogas production can be expected. Also, the lag period of biogas production was reduced at very low TS $(<2 \%)$ which had FD ratios $>1: 9$. The maximum cumulative biogas yield occurred at an FD ratio of 1:19, and biogas production increased almost linearly day 56 days. Methane percentage is reported in Table 2 .

\section{Experiment set 4: effect of FD ratio in semi-batch reactors}

Since the previous experiments were done under batch conditions, to further investigate the effect of feed dilution ratio on biogas production, the authors conducted studies in semibatch reactors. The authors also conducted this experiment 4 under controlled temperature and ambient temperature conditions to see if the increase of specific biogas production with an increase in dilution would take place under both ambient and controlled temperature conditions. Unlike batch reactors which have an unsteady state, the semi-batch reactor system closely represents a real biogas plant and has a steady rate of biogas production. The semi-batch reactor system shown in Fig. 2 was used in experiment set 4 . The effect of different feed ratios and the effect of temperature were studied in semi-batch reactors. There were three sets of reactors, which were $1 \mathrm{CD}: 1 \mathrm{~W}(\mathrm{~A})$ which had 1:1 FD ratio under ambient conditions, 1CD:1W(C), which had 1:1 FD ratio and was under controlled temperature conditions of $37^{\circ} \mathrm{C}, 1 \mathrm{CD}: 3 \mathrm{~W}(\mathrm{C})$, which had 1:3 FD ratio and was under controlled temperature conditions of $37^{\circ} \mathrm{C}$. The experiments 


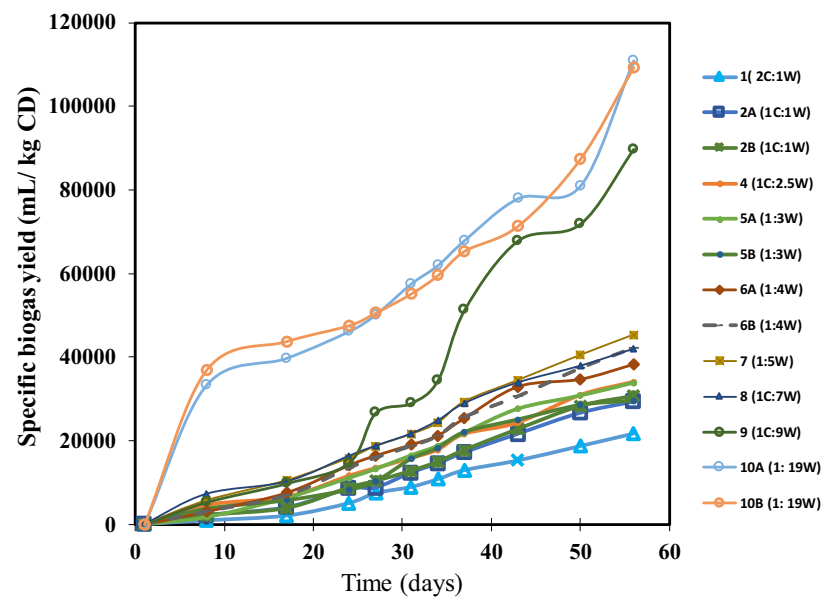

Fig. 5 The cumulative graph to compare biogas yield at different FD ratio

Table 2 Methane \% of different dilution reactors

\begin{tabular}{lll}
\hline SI. no. & Ratio & Methane\% \\
\hline 1 & FDR $2: 1$ & 41.4 \\
2 & FDR $1: 1$ & 52.6 \\
3 & FDR $1: 2$ & 58.9 \\
4 & FDR $1: 2.5$ & 49.9 \\
5 & FDR 1:3 & 39.3 \\
6 & FDR 1:4 & 45.1 \\
7 & FDR 1:5 & 41.2 \\
8 & FDR 1:7 & 43.3 \\
9 & FDR 1:9 & 41.7 \\
10 & FDR 1:19 & 54.5 \\
\hline
\end{tabular}

were carried out in duplicate. The total experiment duration was 55 days. The cumulative biogas yield was plotted vs. time (days) in Fig. 6. From Fig. 6, we can observe that compared to the ambient temperature reactor (1:1A), the higher controlled temperature (1:1C) had higher biogas production by about $21 \%$. The higher FD ratio and higher temperature $1: 3 \mathrm{C}$ has nearly $27 \%$ more biogas compared to $1: 1 \mathrm{C}$ and $52 \%$ more biogas compared to 1:1A. Figure 6 shows the cumulative yield of the biogas at different FD ratios, and it can be seen that the daily biogas yield was higher in the 1:3 FD ratio than the 1:1 FD ratio. The $\mathrm{pH}$ and methane $\%$ of various batches are given in Tables 3 and 4 .

The total solids (TS) of the cow dung used was $20.13 \%$, and the volatile solid content was $16.19 \%$ of the weight. The biogas yield per gram of VS was $232 \mathrm{~mL}, 278 \mathrm{~mL}$, and $319 \mathrm{~mL}$ for the $1: 1 \mathrm{~A}, 1: 1 \mathrm{C}$, and $1: 3 \mathrm{C}$ reactors.

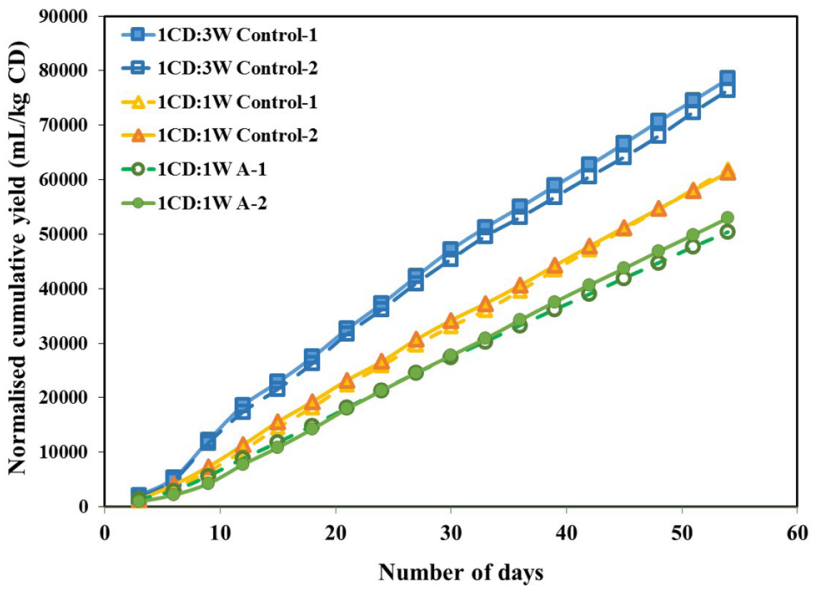

Fig. 6 Cumulative graph to compare biogas yield at different FDR in semi-batch reactors. $C D$ cow dung, $W$ water, $A$ ambient conditions

Table $3 \mathrm{pH}$ values

\begin{tabular}{lll}
\hline SI. no. & Name of the batches & Initial $\mathrm{pH}$ value \\
\hline 1 & 1CD:3W control-1 & 6.79 \\
2 & 1CD:3W control-2 & 6.54 \\
3 & 1CD:1W control-1 & 6.43 \\
4 & 1CD:1W control-2 & 6.25 \\
5 & 1CD:1W A-1 & 6.4 \\
6 & 1CD:1W A-2 & 6.71 \\
\hline
\end{tabular}

\section{Experiment set 5: semi-batch reactor comparing 1:1 and 1:3 feed dilution ratios}

In the final experiment, again, the FD ratios of $1: 1$ and 1:3 were again repeated to compare for their biogas production in another set of semi-batch experiments to see the difference between the two ratios. The reactors with FD ratios of $1: 1(\mathrm{C})$ and $1: 3(\mathrm{C})$ were kept at the same controlled temperature condition of $37{ }^{\circ} \mathrm{C}$. The total experiment was done for 45 days, and the results are given in Fig. 7. From Fig. 7, we can observe that reactor of FD ratio $1: 3$ produced almost $42 \%$ more biogas compared to that of $1: 1$ reactor. These results reinforce the fact that higher FD ratios of about 1:3 are better than 1:1 for increased biogas production. Figure 8 shows the daily biogas production from semi-batch reactors. It can be seen that a steady state was reached after around 20 days. The daily yield of biogas at different FD ratios also consistently higher in the 1:3 FD ratio (C) than the 1:1 FD ratio (C). The $\mathrm{pH}$ (Table 5) and methane $\%$ of various batches were very similar (Table 6) or slightly higher for 
Table 4 Methane \% of different reactors

\begin{tabular}{lll}
\hline SI. no. & Name of the batches & Methane\% \\
\hline 1 & 1CD:3W control-1 & 68 \\
2 & 1CD:3W control-2 & 65 \\
3 & 1CD:1W control-1 & 76 \\
4 & $1 \mathrm{CD}: 1 \mathrm{~W}$ control-2 & 71 \\
5 & $1 \mathrm{CD}: 1 \mathrm{~W}$ A-1 & 64 \\
6 & $1 \mathrm{CD}: 1 \mathrm{~W}$ A-2 & 71 \\
\hline
\end{tabular}

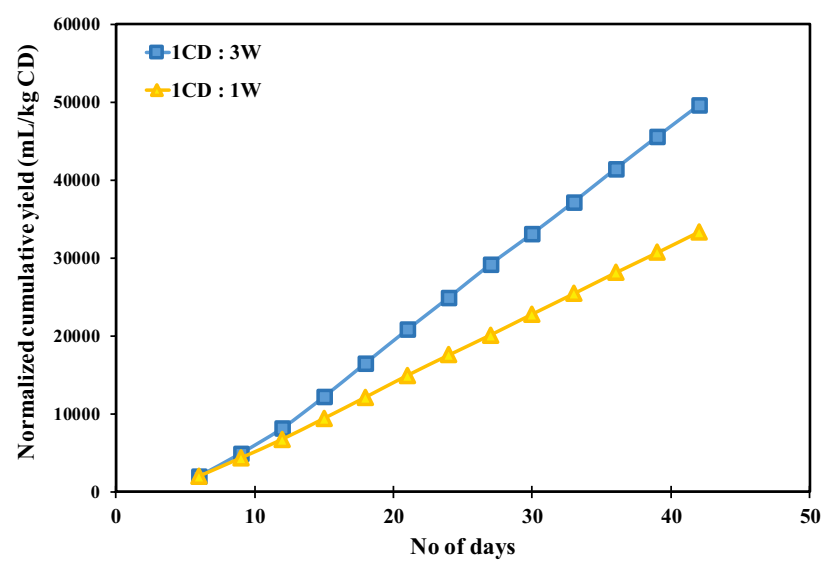

Fig. 7 Normalized cumulative biogas yield of different for feed ratios in semi-batch reactors. $C D$ cow dung, $W$ water, $C D$ cow dung

the 1:1 batch. However, this increase may not be significant and may be offset by the overall increase in the total biogas volume in the 1:3 reactors. The total solids (TS) of the cow dung used was $19.38 \%$, and the volatile solid content was $15.06 \%$ of the weight. The biogas yield per gram of VS was $235 \mathrm{~mL}$, and $356 \mathrm{~mL}$ for the $1: 1$ control reactor and 1:3 control reactors.

\section{Discussion}

The experiments were repeated several times over a period of a three-year period, and similar trends in biogas production with varying dilution were observed. A total of over 1000 man-days of experiments were conducted. We have investigated the effect of feed dilution ratio on substrate inhibition and biogas yield systematically under controlled temperature conditions and ambient temperature conditions. The 1:2 FD ratio reactor produced more biogas than the $1: 1 \mathrm{FD}$ ratio, and the 1:3 FD ratio reactor produced more biogas when compared to the 1:2 FD ratio. The use of 1:3 feed dilution of cow dung in our experiments has shown to increase the yield by nearly $30 \%$ per $\mathrm{kg}$ of cow dung. After the dilution ratio of $1: 3$ or $1: 4$, there is no further significant increase in biogas production. Similarly,

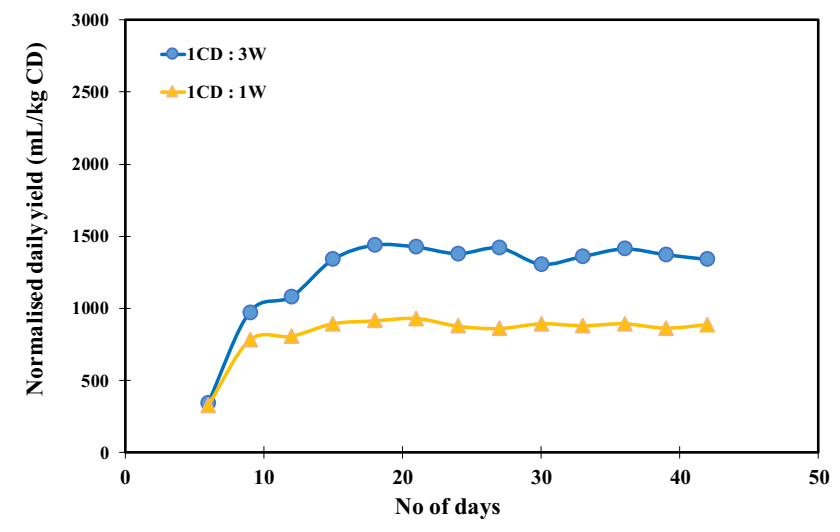

Fig. 8 Daily yield of biogas at different FDR in semi-batch reactors. $C D$ cow dung, $W$ water, $A$ ambient conditions

Table $5 \mathrm{pH}$ values of different reactors

\begin{tabular}{lll}
\hline No. & Biogas reactor & $\mathrm{pH}$ \\
\hline 1 & 1CD:1W control-1 & 6.82 \\
2 & 1CD:3W control-2 & 6.71 \\
\hline
\end{tabular}

Table 6 Methane\% of different reactors

\begin{tabular}{lll}
\hline No. & Biogas reactor & Methane\% \\
\hline 1 & 1CD:1W control-1 & 69 \\
2 & 1CD:3W control-2 & 67 \\
\hline
\end{tabular}

for the distillation bottom product vinasse, it was shown that the dilution ratio of $1: 3$ produced the highest biogas production per gram of COD [33]. The use of a combination of controlled temperature and 1:3 feed dilution ratio can increase the biogas production by nearly $40-50 \%$ (Fig. 7) in semi-batch reactors. This can be done using waste solar heat from solar water heaters and using thermal insulation for biogas plants. Also, the inlet and outlets of the biogas plants have to be sealed to prevent evaporative cooling.

\section{Total solids and dilution ratio}

Total solids (and, hence, feed dilution ratio) are an essential factor affecting biogas productivity. However, the feed dilution ratio or dilution factor is more comfortable to measure and is less prone to measurement errors and delays when compared to total solids. For example, the measurement of total solids requires about $5-6 \mathrm{~h}$ of heating in an oven at $105^{\circ} \mathrm{C}$, which is a cumbersome procedure for most farmers. Measurement of dilution ratio is done much faster in a few 
minutes using simple tools. Since the density of raw cow dung is almost $1000 \mathrm{~kg} / \mathrm{m}^{3}$ [34], it can be approximated to the volume ratio. Hence, the determination of the dilution ratio, which gives the maximum specific biogas yield, is useful. Also, we have noticed that for cow dung, there is a chance of formation of lumps and crusts during oven drying leading to non-uniform drying and trapped moisture while measuring total solids, which can cause errors. The use of the dilution ratio eliminates these errors.

Dilution factor DF, which is commonly used in chemistry, is defined as the ratio of the mass of feed substrate to the total weight (mass of substrate plus the mass of water used for dilution). Since the specific gravity of raw cow dung and water is nearly equal to 1 [34], DF can be approximated as the ratio of respective volumes.

Dilution factor $=\frac{\text { Mass of feed biomass }}{(\text { Mass of feed biomass }+ \text { Mass of water })}$.

As the dilution increases, the dilution ratio and dilution factor increase, and the total solids decrease, and this is represented in Fig. 9 below.

Results from our batch experiments are plotted as specific biogas yields $(\mathrm{mL} / \mathrm{g}$ VS) together with the results of other studies in Fig. 9. The relationship between the dilution ratio, dilution factor, and total solids are also shown in Fig. 9. The figure also compared these results with literature-based results [28, 35-37]. Most of the studies showed that specific biogas production increased with dilution, i.e., increased with a decrease in total solids. Santana and Pound [37] studied biogas production at total solids of $1 \%-8 \%$ for

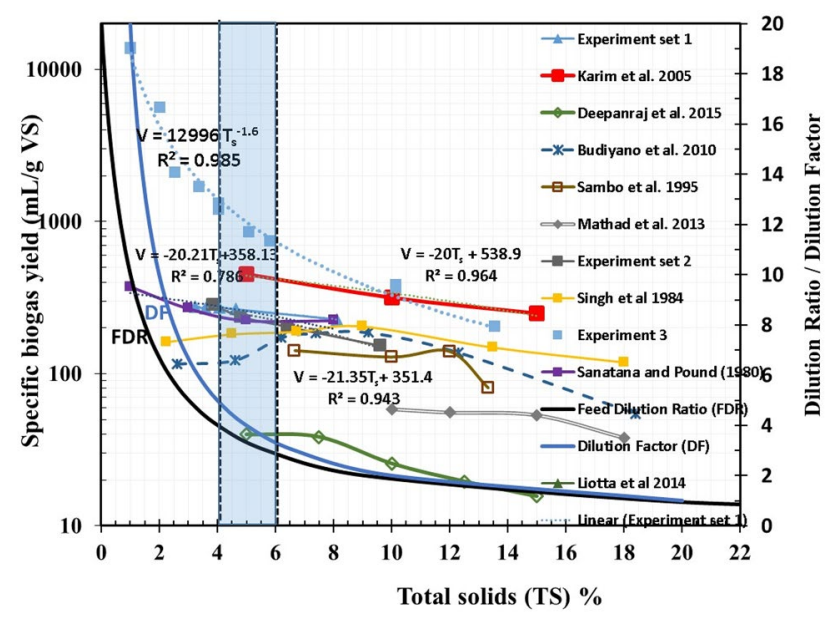

Fig. 9 Variation of specific biogas yield (mL/g VS) with total solids $\%$. A summary of experimental and literature data for biogas yield at different TS, at different feed dilution ratio (FDR) and dilution factor (DF). Each color represents one set of experimental data. FDR is shown in continuous black line and DF as a continuous blue line (color figure online) cattle dung and suggested that $8 \%$ had maximum total biogas production. A study by Budiyano et al. [38] indicated that the best total solids for biogas production were between 7 and $9 \%$. However, they used a very high ratio of rumen fluid of $50 \mathrm{~mL}$ per $100 \mathrm{~g}$ of cow dung and varied the total volume of the reactor, and the methane percentage was not measured. Also, the use of tap water can cause errors due to the chlorine content in tap water. The recent studies [28, 35, 39] support our results that specific biogas yield increases when total solids decrease. A linear relationship exists between TS and specific biogas yield when the TS is greater than 5\%, and when the TS is $<4 \%$, a power-law type of relationship exists as shown in Fig. 9 where $V$ is the specific biogas yield (mL/g VS). $T_{\mathrm{s}}$ is the total solids (mass \%). The $R^{2}$ value of fitting $\sim 0.95$ suggested a good fit. The specific biogas production increases linearly with a decrease in total solids up to a total solid of $4 \%$ and then increases non-linearly.

The relationship equations for specific biogas yield $(V$, $\mathrm{mL} / \mathrm{g}$ VS) as a function of total solids $\left(T_{\mathrm{s}}, \%\right)$ is summarized in Table 7 below.

For a total solids greater than 5\%, a linear relationship exists between specific biogas yield, $V$ and total solids $\left(T_{\mathrm{s}}\right)$ as $V=-21.35 T_{\mathrm{s}}+351.4$, which was got for experiment 2 . A similar relationship $V=-20 T_{\mathrm{s}}+538.9$, was got from literature data [35]. Also, Santana and Pound [37] found a similar relationship as $V=-20.21 T_{\mathrm{s}}+358.13$. The $R^{2}$ value is nearly 0.95 or more, which indicates a good fitting of equation. The equations reveal that an increase in biogas production of $20-21 \mathrm{~mL} / \mathrm{g}$ VS for every $1 \%$ decrease in TS. The intercept of the equation around $350 \mathrm{~mL} / \mathrm{g}$ VS corresponds to the maximum biogas production at very low substrate concentration. The slopes of the equations are similar $(-21.35$ and -20.0$)$, which suggests that the increase in biogas production with a decrease in TS follows a similar trend of nearly an increase of $20 \mathrm{~mL} / \mathrm{g}$ VS for every $1 \%$ reduction in TS. At a TS below 3\%, a power-law type relationship best described the curve $V=12,996 T_{\mathrm{s}}^{-1.6}$, which was obtained from experiment 3 . The $R^{2}$ value of fitting was 0.985 , suggesting very good agreement. This equation indicates that at low TS\%, the specific biogas yield increases rapidly at lower total solids. Similar results were observed in

Table 7 Empirical relationship equations for specific biogas yield ( $V$, $\mathrm{mL} / \mathrm{g}$ VS) as a function of total solids $\left(T_{\mathrm{s}}\right) \%$

\begin{tabular}{llll}
\hline No. & Equations & $R^{2}$ & Source \\
\hline 1 & $V=-21.35 T_{\mathrm{s}}+351.4$ & 0.943 & Exp. set 1 \\
2 & $V=-20.0 T_{\mathrm{s}}+538.9$ & 0.964 & Karim et al. [35] \\
3 & $V=-20.21 T_{\mathrm{s}}+358.13$ & 0.786 & Santana and Pound [37] \\
4 & $V=-20.85 T_{\mathrm{s}}+416.14$ & & Average of 1, 2, 3 \\
5 & $\begin{array}{l}V=129,96 T_{\mathrm{s}}^{-1.6}(\text { at lower } \\
\text { total solids })\end{array}$ & 0.985 & Exp. set 3 \\
\hline
\end{tabular}


earlier studies [19, 23, 27]. This could probably explain why several swamps and polluted water bodies catch fire due to the anaerobic decomposition of organic matter at low TS\%. However, this phenomenon needs further investigation at very low total solids $(<1 \%)$.

Figure 9 suggests that the feed dilution ratio had a major and almost linear influence on the biogas yield in both batch digesters in the range of $4 \%-15 \%$ total solids $\%$. The comparison of Experiment set $1\left(37{ }^{\circ} \mathrm{C}\right)$ and Experiment set 2 (ambient room temperature condition, which is around $25{ }^{\circ} \mathrm{C}$ ) showed that the improvement of biogas production at higher temperatures is less pronounced at lower TS. The temperature effect on biogas production is more noticeable at higher TS than at lower TS. Also, the specific biogas produced in different experiments and literature values varied (Fig. 9), though the substrate was cow dung in all the above studies. This could be due to differences in experimental conditions, variation in the fodder used, and the different breeds of cattle [37]. Nevertheless, the trend of biogas production curves was similar, suggesting similarity of specific biogas production with change in total solids in all the literature data.

The FD ratio of 1:1, 1:2 and FD ratio up to $1: 3$ are economically more viable, and higher dilutions are not used commonly due to reactor volume constraints. This FD ratio range corresponds to the TS of 4 to $10 \%$ if the initial TS of the cow dung is $20 \%$. We also can see that the total solids of around 4\%-6\% are better for higher specific biogas yield (corresponding FD ratio is 1:3-1:4). The results our semibatch reactor experiments [32] support the findings in batch reactors suggesting our results apply to field-scale biogas digesters. However, these lower solid reactors require larger dilution, which means the volume of the reactor increases if we assume the hydraulic retention time to be constant.

Figure 10 shows the comparison of total biogas yield (L/L of reactor volume) and specific biogas yield (mL/g VS) at different initial TS from our experiments and previous studies $[28,38]$. Only data from batch experiments are shown in this figure. From Fig. 9 above, we can see that the total biogas yield ( $\mathrm{L}$ biogas/ $\mathrm{L}$ of reactor volume) increases with the total solids. In contrast, the specific biogas production decreases with the increase of total solids. This is because the increase in the total solids means the availability of more substrate per liter of the reactor, which increases the biogas yield. However, the specific biogas yield reduces with the increase in total solids. This is similar to an example, where the burning of more petrol in the engine leads to more power output, but the efficiency of the engine per liter of petrol reduces.

The total biogas yield in shown in dashed lines and specific biogas yield is shown in continuous lines of same color. The intersection of these lines indicates the optimum range where good total biogas yield and specific biogas yield are

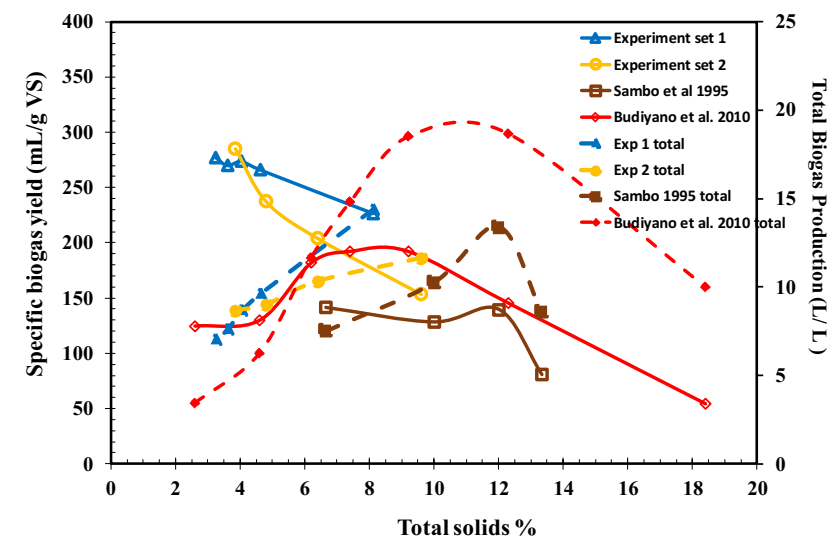

Fig. 10 Comparison of total biogas yield ( $\mathrm{L} / \mathrm{L}$ of reactor volume) and specific biogas yield ( $\mathrm{mL} / \mathrm{g}$ VS) at different TS. Total biogas yield is showed by dashed lines, and specific biogas yield is shown by continuous lines. Each color represents one set of experimental data (color figure online)

achieved. From Fig. 10, we can see that the straight lines for total biogas yield (L biogas/L of reactor volume) and specific biogas yield (mL/g VS) intersect between 5 and $8 \%$ TS. This suggests that the best TS range, where the specific biogas yield is high, total biogas yield ( $\mathrm{L} / \mathrm{L}$ reactor volume) is high, and the FD ratio is also reasonably low is between 5 and $8 \%$. If economy and size of reactor are constraining factors, and a lower size of reactor is desired, then we can choose a dilution ratio of $1.5-2$. This is in contrast with earlier studies which have suggested using TS in the range of $8 \%-15 \%[15,29,30,37,38]$. The recommended TS and feed dilution ratio for better specific biogas yield of cow dung is summarized in Table 4 After a TS of $12 \%-13 \%$, the total biogas production reduces due to inhibition, hence it is not good to operate at $>12.5 \%$ for cow dung-based biogas plants. A similar observation was made by previous studies [15]. A summary of recommended TS and feed dilution ratio for higher specific biogas yield of cow dung is given in Table 8 below. Also, in our experiments, we noted at $\mathrm{TS}=12.5 \%$ (FDR of 2:1), the slurry is too thick and leads to gas being trapped in the slurry, which leads to slurry being levitated into the gas pipes. This phenomenon could lead to choking of the gas outlet, which in turn leads to pressure increase in the reactor, which causes the reactor to structurally fail and leak.

\section{Discussion on inhibition}

The commonly used feed dilution ratio of $1: 1$ could be limited due to substrate inhibition, mixing problems, and mass transfer issues [25-27]. Higher dilution leads to lower viscosity of the slurry, and hence better movement of the mixed microorganisms and also better mass transfer. Lower volatile 
Table 8 Recommended TS and feed dilution ratio for higher specific biogas yield of cow dung, at a initial total solids of $20 \%$

\begin{tabular}{lllll}
\hline No. & Range of TS\% & Dilution ratio & References & Comments \\
\hline 1 & $8 \%$ & $1: 0.8$ & Santana and Pound [37] & \\
2 & $7-9 \%$ & $1: 1-1: 2$ & Budiyono et al. [38] & Used high rumen inoculum \% up to 25\% \\
3 & $9 \%$ & $1: 1$ & Singh et al. [15] & \\
4 & $10 \%$ & $1: 1$ & Acharya [22] & \\
5 & $2.85-4 \%$ & $1: 4-1: 6$ & This study & Extra-large reactor size (very high effi- \\
& & & & ciency) \\
6 & $4-6.7 \%$ & $1: 2-1: 4$ & This study & Large reactor size (high efficiency) \\
7 & $6.7-8 \%$ & $1.5-1: 2$ & This study & Medium reactor size (Medium efficiency) \\
8 & $8-10 \%$ & $1: 1-1: 1.5$ & This study & Small/compact reactor size (low efficiency) \\
\hline
\end{tabular}

solids concentration could also prevent substrate inhibition. Several earlier studies have suggested that at higher total solids, substrate inhibition could take place. Battista et al. [20] found that that polyphenols could inhibit biogas production at lower dilution ratios during the biodigestion of olive oil production wastes. Higher concentrations of ammonium ions and free ammonia causes inhibition of anaerobic digestion $[40,41]$. Several studies have shown that mixing improves biogas production [35] by reducing the mass transfer limitations. Hence, the commonly used 1:1 FD ratio is inhibited, and the specific biogas production can be increased by dilution.

\section{Hydraulic retention time}

When the FD ratio is increased from 1:1 to $1: 2$ onwards, the reactors need to be suitably increased in size so as maintain the hydraulic retention time (HRT) required. Thankfully, many of the older reactors have been over-designed, so the dilution ratio can be increased even in older biogas reactors without affecting the HRT much. Future biogas plants can be designed at a higher FD ratio of 1:2 or 1:3 or low TS around $5 \%-8 \%$ for the maximum specific biogas yield and higher efficiency. Higher HRT also gives improved specific biogas yield [40]. Hence, an HRT of 50 days may be used instead of 40 days. However, the limitation of using the higher dilution ratio is that it will also require a larger reactor size, which will increase the initial investment of the biogas plant. Hence, an optimum value of HRT and total solids must be chosen to keep the initial investment within the budget and have a lower payback period on investment. Thus although the lower total solid of 5\%-6\% gives a better maximum specific yield, due to higher costs, it may not be viable to adopt the lower total solids in plant design. If economy and size of reactor are constraining factors, and a lower size of reactor is desired, then we can choose a dilution ratio of 1.5-2. Also, more water will be required for higher dilutions. Nevertheless, water is usually available on farms, and the effluent from the biogas plant can be reused for agriculture and as a fertilizer.
However, if a higher total biogas yield per unit volume of the reactor is desired in already existing biogas plants, then higher total solids such as may be used. In this case, the effect of inhibition will be overcome by the total increase of higher total solids available in the reactor. Though such a reactor will be biomass/energy inefficient and the specific biogas yield will be lower, its overall biogas output will be higher due to the higher biomass used.

\section{Semi-batch vs. batch reactors}

Studies from batch reactors cannot be applied to directly fieldscale biogas plants, which operate in semi-batch mode [31]. The biogas production in batch and semi-batch reactors are different (e.g., Figs. 4, 5, 6, and 7). The overall biogas batch production in batch reactors reaches a plateau after 50 days, whereas the biogas production in semi-batch reactors keeps increasing linearly. For example, the extent of biomass degradation and gas generation was different by nearly $20 \%$ [31] in batch and semi-batch. In batch reactors, the microorganisms undergo lag phase, log phase, and decay phase [41], whereas a steady stage is established in semi-batch reactors.

The biogas production increase in the 1:3 FD ratio was more prominent in the semi-batch reactors when compared to the batch reactors. This increase could be due to the steady-state process in the semi-batch reactors. This observation is supported by Singh [15], who suggested that biodegradation in semi-batch reactors was nearly $20 \%$ higher than in batch reactors.

Semi-batch reactors gave a higher biogas yield than the batch reactors and were more stable in biogas yield. The methane percentage in the semi-batch reactors was also higher than the methane $\%$ of the batch reactors.

\section{Conclusions}

As the FD ratio is increased from 1:1 to a higher FD ratio (cowdung slurry dilution is increased), the specific biogas production increased significantly. A larger 
FD ratio possibly reduced the inhibition caused by mass transfer, mixing limitations, and ammonia concentrations. A plot of total solids (TS) vs specific biogas production was done by compiling available experimental and literature data. This plot clearly showed that the specific biogas production ( $\mathrm{mL} / \mathrm{g} \mathrm{VS}$ ) increases as the total solids (\%) reduces. A negative linear relationship exists between TS and specific biogas yield at TS $>4 \%$, and when the TS is $<4 \%$, a power-law type of relationship exists. Semibatch experiments suggest that a combined total increase of nearly $40 \%-50 \%$ yield may be obtained using the higher mesophilic temperature $\left(37^{\circ} \mathrm{C}\right)$ combined with a higher FD ratio of 1:3, compared to using a 1:1 FD ratio under ambient temperature reactors. The results from semi-batch reactors support the findings in batch reactors suggesting that our batch experiment results could apply to field-scale biogas digesters.

The author recommended TS and feed dilution ratio for higher specific biogas yield of cowdung is summarized in Table 8. To achieve a higher specific biogas yield efficiency, the authors recommend using lower total solids of around 4\%-6.7\% (FD ratio of 1:2-1:4) for biogas plants compared to the conventionally used total solids of $8 \%-10 \%$ (FD ratio of 1:1 to 1:1.5. Further, using a stable higher mesophilic range temperature of $30-40{ }^{\circ} \mathrm{C}$ in combination with lower TS is recommended for the production of maximum specific biogas yield. The optimum total solids range, where the specific biogas yield is high, total biogas yield (L/L reactor volume) is also high, and the FD ratio is also reasonably low is between 6.67 and $8 \%$ $(1: 1.5-1: 2)$.

Acknowledgements The authors would like to thank Prof. SVSR Krishna Bandaru, Prof. Balakrishna Prabhu, Prof. Harishkumar, Dr. Nethaji S., Ms. Sneha Ramesh, Mr. Sadananda Tendulkar, and all their colleagues. The authors also thank Dr. Arunkumar Thalla, Dr. Pruthviraj, Mr. Manohar Shanubogue, Mr. Sanjeev, Ms. Adhira, and Dr. Uma Shaktivel from the Civil Engineering Department of NITK., Surathkal. Also, the authors thank Dr. Bhasker Jha, and Prof. V.K. Vijaykumar of CRDT in IIT. Delhi. The authors would like to thank Mr. Himanshu, Ms. Ivy (exchange scholar), Mr. Ankit Shettty, Mr. Siddarth Mitra, Mr. Kevin Lobo, Mr. Amitabh Roy, Mr. Nikil, Mr. Kripesh, Ms. Aspha Mohanty and Mr. Mubeen for the help in experiments. The authors would like to thank the Karnataka Government and the Vision group on science and Technology (RGS/F GRD 696) for funding this work. The authors also thank the Karnataka state council state for science and technology (KSCST) for the funding (Grant No.41S_B_BE_099 SPP-Biofuels). The authors also thank the anonymous reviewers for their suggestions which greatly improved the manuscript.

Funding Open access funding provided by Manipal Academy of Higher Education, Manipal.

\section{Declarations}

Conflict of interest The authors declare that there is no conflict of interest.
Open Access This article is licensed under a Creative Commons Attribution 4.0 International License, which permits use, sharing, adaptation, distribution and reproduction in any medium or format, as long as you give appropriate credit to the original author(s) and the source, provide a link to the Creative Commons licence, and indicate if changes were made. The images or other third party material in this article are included in the article's Creative Commons licence, unless indicated otherwise in a credit line to the material. If material is not included in the article's Creative Commons licence and your intended use is not permitted by statutory regulation or exceeds the permitted use, you will need to obtain permission directly from the copyright holder. To view a copy of this licence, visit http://creativecommons.org/licenses/by/4.0/.

\section{References}

1. Thornton PK (2010) Livestock production: recent trends, future prospects. Philos Trans R Soc B Biol Sci 365:2853-2867. https:// doi.org/10.1098/rstb.2010.0134

2. Lohan SK, Dixit J, Kumar R et al (2015) Biogas: a boon for sustainable energy development in India's cold climate. Renew Sustain Energy Rev 43:95-101

3. Lissens G, Thomsen AB, De Baere L et al (2004) Thermal wet oxidation improves anaerobic biodegradability of raw and digested biowaste. Environ Sci Technol. https://doi.org/10.1021/es035092h

4. Cheng XY, Zhong C (2014) Effects of feed to inoculum ratio, codigestion, and pretreatment on biogas production from anaerobic digestion of cotton stalk. Energy Fuels. https://doi.org/10.1021/ ef $402562 z$

5. Bruni E, Jensen AP, Angelidaki I (2010) Comparative study of mechanical, hydrothermal, chemical and enzymatic treatments of digested biofibers to improve biogas production. Bioresour Technol. https://doi.org/10.1016/j.biortech.2010.06.108

6. Kreuger E, Sipos B, Zacchi G et al (2011) Bioconversion of industrial hemp to ethanol and methane: the benefits of steam pretreatment and co-production. Bioresour Technol. https://doi.org/10. 1016/j.biortech.2010.10.126

7. Zheng Y, Zhao J, Xu F, Li Y (2014) Pretreatment of lignocellulosic biomass for enhanced biogas production. Prog Energy Combust Sci 42:35-53

8. Trivedi A, Verma AR, Kaur S et al (2017) Sustainable bio-energy production models for eradicating open field burning of paddy straw in Punjab, India. Energy. https://doi.org/10.1016/j.energy. 2017.03.138

9. Clark PB, Hillman PF (1996) Enhancement of anaerobic digestion using duckweed (lemna minor) enriched with iron. Water Environ J. https://doi.org/10.1111/j.1747-6593.1996.tb00015.x

10. Liu C, Yuan H, Zou D et al (2015) Improving biomethane production and mass bioconversion of corn stover anaerobic digestion by adding $\mathrm{NaOH}$ pretreatment and trace elements. Biomed Res Int. https://doi.org/10.1155/2015/125241

11. Patel VB, Patel AR, Patel MC, Madamwar DB (1993) Effect of metals on anaerobic digestion of water hyacinth-cattle dung. Appl Biochem Biotechnol. https://doi.org/10.1007/BF02916429

12. Preeti Rao P, Seenayya G (1994) Improvement of methanogenesis from cow dung and poultry litter waste digesters by addition of iron. World J Microbiol Biotechnol. https://doi.org/10.1007/ BF00360890

13. Yadvika S, Sreekrishnan TR et al (2004) Enhancement of biogas production from solid substrates using different techniques-a review. Bioresour Technol 95:1-10. https://doi.org/10.1016/j.biort ech.2004.02.010

14. Motte JC, Trably E, Escudié R et al (2013) Total solids content: a key parameter of metabolic pathways in dry anaerobic digestion. Biotechnol Biofuels. https://doi.org/10.1186/1754-6834-6-164 
15. Singh R, Malik RK, Jain MK, Tauro P (2014) Biogas production at different solids concentrations in daily fed cattle waste digesters. Agric Wastes 11:253-257. https://doi.org/10.1016/ 0141-4607(84)90033-7

16. Liu XL, Wang MM, Hu XJ, Song YH (2014) Effect of total solids content on the biogas production and phosphorus release from excess sludge. Adv Mater Res 1010-1012:1006-1009. https://doi. org/10.4028/scientific.net/AMR.1010-1012.1006

17. Liotta F, D'Antonio G, Esposito G et al (2014) Effect of total solids content on methane and volatile fatty acid production in anaerobic digestion of food waste. Waste Manag Res 32:947-953. https://doi.org/10.1177/0734242X14550740

18. Deepanraj B, Sivasubramanian V, Jayaraj S (2015) Experimental and kinetic study on anaerobic digestion of food waste: the effect of total solids and pH. J Renew Sustain Energy 7:063104. https:// doi.org/10.1063/1.4935559

19. Leite VD, Viriato CL, De Sousa JT et al (2018) Anaerobic codigestion of organic waste: influences particle size and concentration total solids. J Solid Waste Technol Manag 44:153-162. https://doi.org/10.5276/jswtm.2018.153

20. Battista F, Fino D, Ruggeri B (2014) Polyphenols concentration's effect on the biogas production by wastes derived from olive oil production. Chem Eng Trans. https://doi.org/10.3303/CET14 38063

21. Chandra R, Vijay VK, Subbarao PMV (2006) A study on biogas generation from non-edible oil seed cakes : potential and prospects in India. In: 2nd joint international conference on "Sustainable Energy and the Environment" (SEE 2006)

22. Acharya CN (1958) Preparation of fuel gas and manure by anaerobic fermentation of organic materials. Indian Counc Agric Res Bull 15:115

23. Itodo IN, Awulu JO (1999) Effects of total solids concentrations of poultry, cattle, and piggery waste slurries on biogas yield. Trans Am Soc Agric Eng. https://doi.org/10.13031/2013.13350

24. Achkari-Begdouri A, Goodrich PR (1992) Rheological properties of Moroccan dairy cattle manure. Bioresour Technol 40:149-156. https://doi.org/10.1016/0960-8524(92)90201-8

25. Webb AR, Hawkes FR (1985) The anaerobic digestion of poultry manure: variation of gas yield with influent concentration and ammonium-nitrogen levels. Agric Wastes 14:135-156. https://doi. org/10.1016/S0141-4607(85)80025-1

26. Chen Y, Cheng JJ, Creamer KS (2008) Inhibition of anaerobic digestion process: a review. Bioresour Technol 99:4044-4064. https://doi.org/10.1016/j.biortech.2007.01.057

27. Abbassi-Guendouz A, Brockmann D, Trably E et al (2012) Total solids content drives high solid anaerobic digestion via mass transfer limitation. Bioresour Technol 111:55-61. https://doi.org/ 10.1016/j.biortech.2012.01.174
28. Sambo AS, Garba B, Danshehu BG (1995) Effect of some operating parameters on biogas production rate. Renew Energy 6:343344. https://doi.org/10.1016/0960-1481(95)00027-H

29. Zennaki-Bensouda Z, Zaid A, Lamini H et al (1996) Methane fermentation of cattle manure: effects of hydraulic retention time. Temperature and substrate concentration. Tropicultura 14:134-140

30. Liu Z, Lv J (2016) The effect of total solids concentration and temperature on biogas production by anaerobic digestion. Energy Sources A Recover Util Environ Eff 38:3534-3541

31. Jain MK, Singh R, Tauro P (1983) Cattle waste anaerobic digestion in a semi-continuous and a batch digester. Agric Wastes 7:251-259. https://doi.org/10.1016/0141-4607(83)90046-X

32. Janardhanan $\mathbf{J}$ (2018) Optimization of biogas production in various reactors and by using different chemical additives. Manipal Institute of Technology

33. Budiyono SI, Sumardiono S (2014) Effect of total solid content to biogas production rate from vinasse. Int J Eng Trans B Appl 27:177-184. https://doi.org/10.5829/idosi.ije.2014.27.02b.02

34. Chen YR (1983) Thermal properties of beef cattle manure. Agric Wastes 6:13-29. https://doi.org/10.1016/0141-4607(83)90003-3

35. Karim K, Hoffmann R, Klasson KT, Al-Dahhan MH (2005) Anaerobic digestion of animal waste: effect of mode of mixing. Water Res 39:3597-3606. https://doi.org/10.1016/j.watres.2005. 06.019

36. Mathad et al (2013) Performance of cattle dung at different total solids in prototype digesters for biogas production. Int J Agric Eng 6:431-433. http://ischolar.info/index.php/Ijae/article/view/48479

37. Santana A, Pound B (1980) The production of biogas from cattle slurry, the effects of concentration of total solids and animal diet. Trop Anim Prod. 1980:5:2. https://www.cipav.org.co/TAP/TAP/ TAP52/5_2_5.pdf.

38. Budiyono IN, Johari S, Sunaraso S (2010) The influence of total solid contents on biogas yield from cattle manure using rumen fluid inoculum. Energy Res J 1:6-11. https://doi.org/10.3844/ erjsp.2010.6.11

39. Rajeshwar M, Vijayakumar P, Desai SR, Sunil S (2013) Performance of cattle dung at different total solids in prototype digesters for biogas production. Int J Agric Eng 6:431-433

40. Boodoo A, Delaitre C, Preston TR (1977) The effect of retention time on biogas production from slurry produced by cattle fed sugar cane. Trop Anim Prod 4(1):21-25

41. McCarty PL, McKinney RE (1961) Salt toxicity in anaerobic digestion. Water Pollut Control Fed 33:223-232. https://www. scirp.org/(S(351jmbntvnsjt1aadkposzje))/reference/References Papers.aspx ?ReferenceID $=1570599$

Publisher's Note Springer Nature remains neutral with regard to jurisdictional claims in published maps and institutional affiliations. 